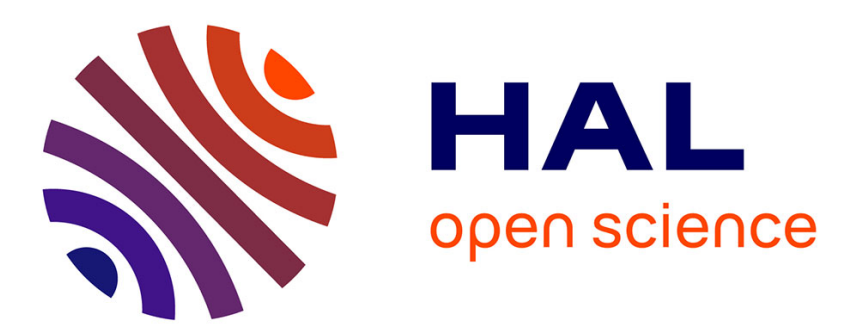

\title{
Edge modification of PAHs: the effect of embedded heterocycles on the aromaticity pattern
}

Rózsa Szűcs, Pierre-Antoine Bouit, Muriel Hissler, László Nyulászi

\section{To cite this version:}

Rózsa Szűcs, Pierre-Antoine Bouit, Muriel Hissler, László Nyulászi. Edge modification of PAHs: the effect of embedded heterocycles on the aromaticity pattern. Structural Chemistry, 2015, 26, pp.13511357. 10.1007/s11224-015-0665-x . hal-01200778

\section{HAL Id: hal-01200778 \\ https://hal-univ-rennes1.archives-ouvertes.fr/hal-01200778}

Submitted on 23 Sep 2015

HAL is a multi-disciplinary open access archive for the deposit and dissemination of scientific research documents, whether they are published or not. The documents may come from teaching and research institutions in France or abroad, or from public or private research centers.
L'archive ouverte pluridisciplinaire HAL, est destinée au dépôt et à la diffusion de documents scientifiques de niveau recherche, publiés ou non, émanant des établissements d'enseignement et de recherche français ou étrangers, des laboratoires publics ou privés. 


\title{
Edge Modification of PAHs. The effect of embedded heterocycles on the aromaticity pattern
}

\author{
Rózsa Szűcs, Pierre-Antoine Bouit, Muriel Hissler*, László Nyulászi*
}

\section{Affiliations}

R. Szücs, L. Nyulászi

Department of Inorganic and Analytical Chemistry, Budapest University of Technology and Economics, Szt. Gellért tér 4, Budapest 1111, Hungary

e-mail:nyulaszi@mail.bme.hu

\section{R. Szücs, P-A. Bouit, M. Hissler}

Institut des Sciences Chimiques de Rennes, UMR6226 CNRS-Université de Rennes 1, Campus de Beaulieu, 35042

Rennes Cedex, France

e-mail: muriel.hissler@univ-rennes1.fr

Deadicated to Professor Magdolna Hargittai on the occasion of her 70th birthday.

\section{Introduction}

Polycyclic aromatic hydrocarbons (PAHs) are important targets of experimental and theoretical studies, because of their potential use in optical and electronic devices such as light-emitting devices, field-effect transistors and photovoltaics [1].

In these types of applications electronic properties of the molecule are of crucial importance. Aromaticity [2-5] is one of the key concepts related to the electronic structure. Its exploitation gives important application-related information about the system. Differences in local aromaticity give good explanation to isomer stability, such as the superior stability of armchair edges to zigzag ones in graphene nanoribbons [6, 7]. Additionally, it influences the selectivity of reactions as in the case of Diels-Alder cycloadditions to fullerenes [8] or the addition pattern of fluorine to carbon nanotubes [9]. Generally, local aromaticity patterns in PAH systems, can be interpreted with Clar's aromaticity rule [10], which states that the Kekulé resonance structure with the largest number of disjoint $\pi$-sextets is the most important for the characterisation of a molecule, and the local aromaticity is increased in case of $\pi$-sextet bearing rings. Clar's rule is in good agreement with both theoretical and experimental results for similar system types [11-13] and can be used to design PAHs with specific electronic properties [14].

The properties of PAH systems can be modified with embedding heteroatoms into the $\mathrm{sp}^{2}$ backbone [15-20]. In particular, phosphole is a unique building block, because compared to many of its heterocyclic analogues, it has a weak aromatic character [21, 22]. Furthermore, previously we have shown on phosphole oligomers that with chemical modifications on the reactive $\mathrm{P}$-atom even slight antiaromaticity is obtainable [23]. Recently we synthetized and studied PAHs containing a phosphole unit on the edge
(Figure 1) and found that the presence of the heterocycle has a strong effect both on the frontier molecular orbitals [24] and the local aromaticity pattern of the PAH backbone [25]. Most interestingly, we observed that not only the five-membered ring of $\mathbf{1}$ possesses weak antiaromatic NICS(1) values, as expected, but the antiaromaticity spreads over also to the endocyclic six-membered ring annellated to the phosphole's 3,4 position. This intrusion of the antiaromaticity is creating an antiaromatic strip in the symmetry-axis of the molecule (Figure 1) [25]. Furthermore, by modification of the P-substituents not only the NICS aromaticity of the five-membered ring was tuned, but also that of the neighbouring endocyclic sixmembered unit.

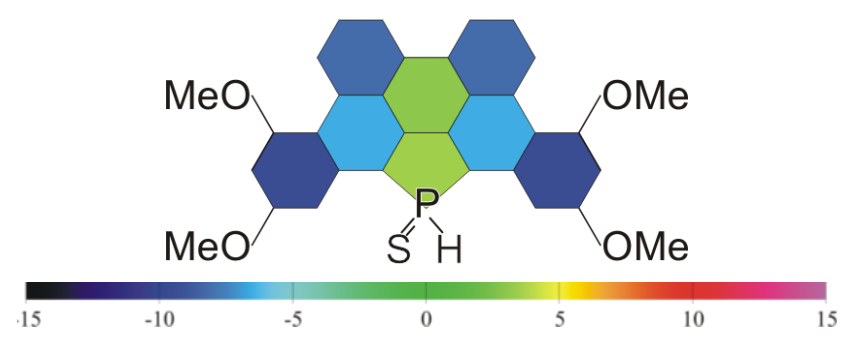

Figure 1. Schematic representation of the B3LYP/6-31+G* NICS(1) pattern of the phosphole-containing PAH (1) investigated before [25].

As an extension of our previous work, we hereby investigate the aromaticity patterns, focusing on the endocyclic six-membered ring and its aromaticity change induced by the different neighbouring five-membered rings, to get generalizable conclusions. To this end, we consider different building blocks from creating highly aromatic systems (for example: $\mathrm{NH}$ or $\mathrm{S}$ ) to clearly antiaromatic systems (such as BH), spanning a much wider aromaticity scale than studied before. For the PAH unit we have chosen the ring system studied before, since this has a closed shell ground state [26] but in our model system 2 
we do not include the methoxy groups, which were only needed for synthetic reasons [24, 25] in case of $\mathbf{1}$. The targeted heterocycle-embedded structures of $\mathbf{2}$ are shown in Figure 2. For further tuning of the aromaticity of the heterocycle, (when applicable) we consider substituents on the heteroatom, which exhibit large hyperconjugative effects (R: $\left.\mathrm{SiH}_{3}, \mathrm{~F}\right)$ [27]. For comparison three reference molecules - containing no heteroatoms - have been investigated (Figure 3). In R1, the investigated sixmembered ring has no five-membered neighbour, and in case of $\mathbf{R 2}$, the five-membered ring is non-aromatic [27]. $\mathbf{R 3}$ has a (Clar-)aromatic six-membered ring annellated to the endocyclic six-membered one.

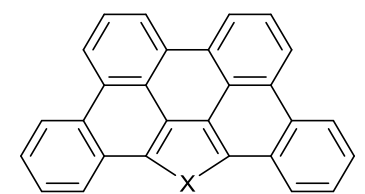

X: BR; NR; O; $\mathrm{SiR}_{2} ; \mathrm{PR} ; \mathrm{P}(\mathrm{O}) \mathrm{R}$; $\mathrm{POOH} ; \mathrm{PR}_{2}^{+} ; \mathrm{S} ; \mathrm{SO} ; \mathrm{SO}_{2} ; \mathrm{GeR}_{2}$; AsR; As(O)R; AsOOH; $\mathrm{AsR}_{2}^{+}$; $\mathrm{Se} ; \mathrm{SeO} ; \mathrm{SeO}_{2}$

R: $-\mathrm{H} ;-\mathrm{F} ;-\mathrm{SiH}_{3}$

Figure 2. The investigated heterocycle-containing structure 2 , with different hetero groups.

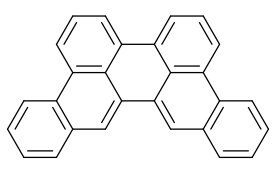

R1

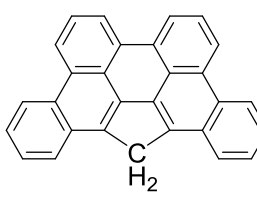

R2

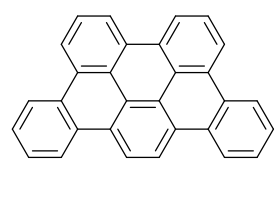

R3
Figure 3. The investigated reference molecules arsole and selenophene derivatives. To investigate the effect of the electron donating or withdrawing groups present on the heteroatom, when applicable $-\mathrm{SiH}_{3},-\mathrm{H}$ and - F substituents were used.

Structures will be referred to by the symbol of the heteroatom. Oxides will be referred to by an $\mathbf{O}$, cationic derivatives by a + after the symbol of the heteroatom. The substituent present is indicated after the dash. For instance: 2PO-F refers to the compound in Figure 2, where $\mathrm{X}: \mathrm{P}(\mathrm{O}) \mathrm{F}$

\section{Results and discussion}

\section{Aromaticity}

Before investigating the extended systems, the aromaticity of the parent rings (Table 1) has been calculated at the highest used level of theory (B3LYP/cc-pVTZ). The results (summarized in Table 1) are in good agreement with the values published previously at a somewhat different level of theory [42]. As expected, NICS(1) values span a wide range between -10.7 for tiophene, a highly aromatic ring and +11.6 for antiaromatic borole. In case of P, PO, As and AsO systems the two NICS(1) values differ slightly, as a consequence of the asymmetry on the heteroatom. For the visualisation of the larger systems, and for the correlations (see below) we use the average of the two values.

\section{Computational methods}

Although the concept of aromaticity is well-known, its description and quantification is still difficult. There are multiple approaches to describe this phenomenon, the most commonly used methods are using either geometry-based, energetic, electronic or magnetic descriptors [3, 28-34]. Each of these methods have their limitation, but in general cases they show significant collinearity [35]. Studies in the case of PAHs and fullerenes confirm that the use of the magnetic based method, nucleus independent chemical shift (NICS) [36, 37] is in good agreement with other types of descriptors and gives reliable results for these systems. [38]

In the present work the Gaussian 09 program package [39] was used to perform the calculations. Full geometry optimisations and further investigations $(\operatorname{NICS}(0)$ [36] and NICS(1) [37] calculations) have been carried out with the B3LYP [40, 41] functional with three different basis sets: 6-31G*, 6-31+G*, cc-pVTZ. This was done in order to test the applicability of the basis sets, with the intention of using the smaller basis sets in future projects, concentrating on these types of systems with increased size.

The investigated structures of $\mathbf{2}$ (Figure 2) cover borole, pyrrole, furane, silole, phosphole, thiophene, germole, 
Table 1: NICS aromaticity of parent heterocycles at the B3LYP/cc-pVTZ level. In case of dissymmetric molecules slightly different NICS(1) values were obtained at the two sides of the ring, in the table these values are separated by a slash.

\begin{tabular}{|c|c|c|c|c|c|}
\hline $\operatorname{NICS}(0)$ & -8.2 & +20.3 & -14.0 & -11.9 & +0.8 \\
\hline NICS(1) & -10.4 & +11.6 & -10.5 & -9.6 & -1.3 \\
\hline
\end{tabular}
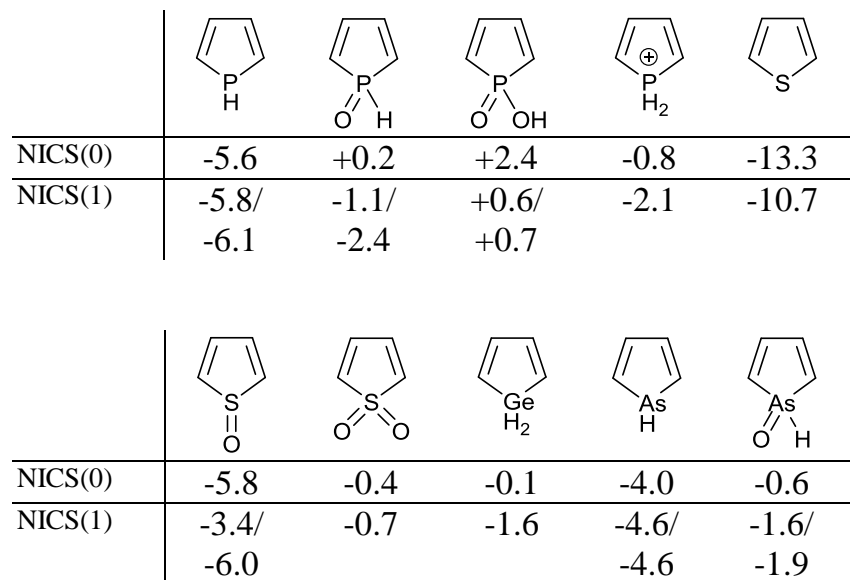

\begin{tabular}{|c|c|c|c|c|c|}
\hline NICS $(0)$ & +0.5 & -1.3 & -12.5 & -2.1 & -1.3 \\
\hline NICS(1) & $\begin{array}{l}-0.2 / \\
-04\end{array}$ & -2.0 & -10.0 & $\begin{array}{l}-1.7 / \\
-32\end{array}$ & -1.3 \\
\hline
\end{tabular}

In the following part, we investigated NICS aromaticity patterns of systems based on dibenzo[ $f g, i j]$ pentaphene (R1), focusing on the correlation between the aromaticity of the different (hetero)cycles incorporated at the edge of the structure and that of the endocyclic six membered ring. (Figure 4 and Figure 5).
Investigation of the aromaticity of the reference molecules $\mathbf{R 1}, \mathbf{R 2}$ and $\mathbf{R 3}$ (Figure 4) shows that the aromaticity pattern corresponds well with the Clar-structure, the rings bearing the $\pi$-sextets are significantly more aromatic then their neighbours $(\triangle \mathrm{NICS}(1) \approx 7 \mathrm{ppm})$. The endocyclic sixmembered ring in the symmetry axis is slightly antiaromatic in case of R1. Though the presence of nonaromatic cyclopentadiene unit in $\mathbf{R 2}$ changes the value slightly, the antiaromatic character prevails. Oppositely, in case of $\mathbf{R 3}$ the endocyclic ring gains some aromaticity according to the NICS(1) values, as a consequence of having the highly aromatic connecting benzene unit (Figure 4).

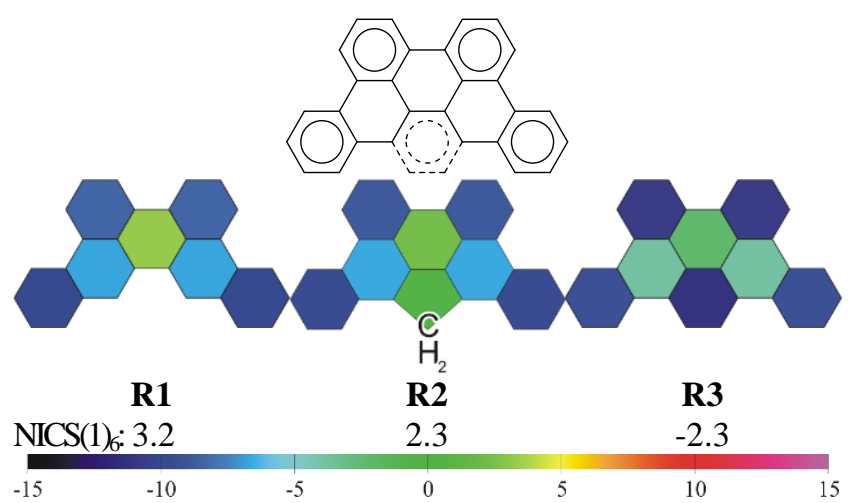

Figure 4:Clar-structure and NICS(1) aromaticity pattern of $\mathbf{R} \mathbf{1 - 3}$

Study of these non-heteroatom-containing systems confirmed that the aromaticity of the endocyclic ring in question is influenced by the connecting unit. To study the extent of this dependence we further diversify the properties of the connecting cycle, by the introduction of heteroatoms.

(Figure 


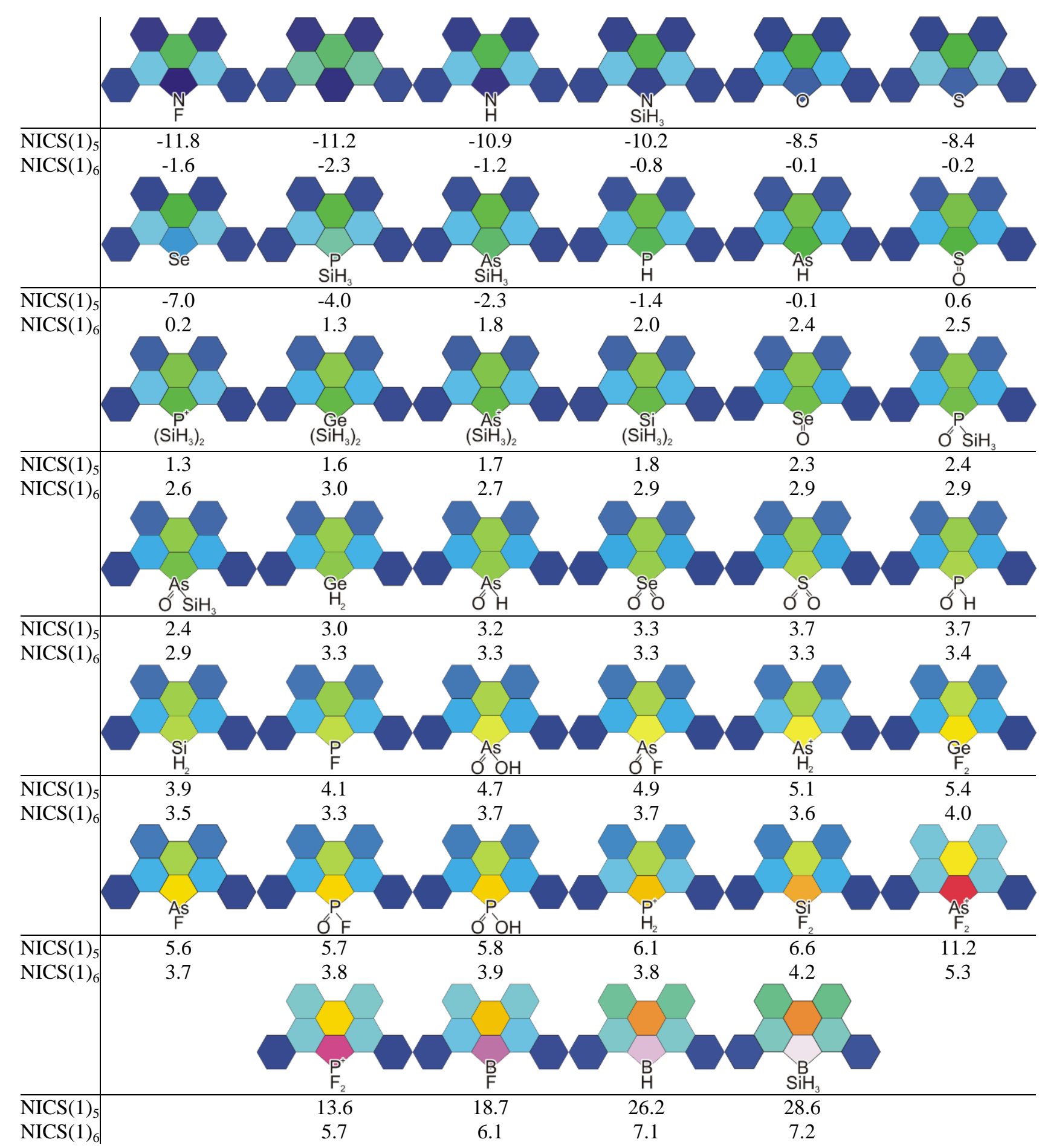

$\begin{array}{llllllllll}-15 & -10 & -5 & 0 & 5 & 10 & 15 & 20 & 25 & 30\end{array}$

Figure 5: NICS (1) aromaticity patterns and the average NICS(1) aromaticity values of the rings at the axis of symmetry at the B3LYP/cc-pVTZ level. For numeric results for all rings see Table S5 in the Supporting Information, where both NICS(1) values are presented in case of the asymmetric systems. The darkness of the ring is related to the NICS(1) aromaticity, as shown by the scale at the bottom of the figure. NICS $(1)_{5}$ and NICS $(1)_{6}$ refer to the corresponding (average) values of the five-membered and the endocyclic sixmembered rings, respectively.

The NICS $(1)_{5}$ values in the five-membered rings of $\mathbf{2}$ (Figure 5) reflect the values of the parent five-membered ring, as it is shown by the linear correlation presented in Figure 6. It is noteworthy that the correlation coefficient is somewhat reduced $\left(\mathrm{R}^{2}=0.8728\right)$, if the values for the $\mathrm{F}$ and $\mathrm{SiH}_{3}$ substituted systems are also included (see the grey points in Figure 6). It is noteworthy that the NICS values of the antiaromatic five-membered rings are much higher 
in 2 (Figure 5) than in case of the parent isolated systems (Table 1). These values, however fit into the linear correlation. We have also checked the stability of the wavefunction for these antiaromatic systems, but no instability was found. All this indicates that the huge NICS(1) values are not artefacts.

The NICS(1) values of the endocyclic six-membered rings (NICS $(1)_{6}$ values) are significantly influenced by the heteroatom in the five-membered ring. Comparison between the purely benzenoid structure (R3) and heterocycle-embedded systems shows that although the aromaticity pattern corresponds well with the Clarstructures (Figure 4) in every case as it was already noted for PAH's [43, 44], the heterocycles can modify the magnetic properties of their surroundings. (See Figure 5)

In relation with the similar NICS(1) aromaticity values of pyrrole, thiophene, furan and benzene, the NICS $(1)_{6}$ values of the endocyclic rings in $\mathbf{2 N}, \mathbf{2 O}$ and $\mathbf{2 S}$ exhibit almost identical values with the corresponding ring in R3. With the decreasing aromaticity in the five-membered ring (e.g. 2P, 2As, 2Si, 2PO, 2Ge and 2AsO), the NICS(1) 6 values shift gradually to the more positive region indicating increasing antiaromaticity, the largest positive $\operatorname{NICS}(1)_{6}$ values are exhibited by $\mathbf{2 B}$, in accordance with the large positive $\mathrm{NICS}(1)_{5}$ values.

Clearly, the aromaticity of the endocyclic six-membered ring is related to the aromatic character of the neighbouring five-membered heterocycle, as it is shown in Figure 7. NICS $(1)_{6}$ results show a significant correlation with
$\mathrm{NICS}(1)_{5}$ (linear regression: $\mathrm{R}^{2}=0.9253$; and an even much better second degree polynomial regression: $\left.\mathrm{R}^{2}=0.9920\right)$. The aromaticity of the endocyclic six-membered ring's is anchored to the slightly antiaromatic value in the reference molecules R1 (+3.2) and R2 (+2.3), and altogether the values between $-2.3(\mathbf{R 3})$ to $+7.2\left(\mathbf{2 B}-\mathbf{S i H}_{\mathbf{3}}\right)$ span a nearly $10 \mathrm{ppm}$ range variation in the magnetic shielding on the NICS(1) scale.

Geometry-based aromaticity indices have also been calculated and results have been compared to those obtained by the magnetic-based NICS. The geometric indices used are based on different aspects of aromaticity, Bird [45-48] index is connected to the standard deviation of the Gordy bond orders [49] within the ring, while BDSHRT [50] shows the average $\pi$-type bond order. (For B3LYP/cc-pVTZ data see Table S6 and Figures S7-8). Although as previous studies suggested all the investigated aromaticity measures correlate with each other [35], this correlation is relatively weak (especially in case of the Bird index) In case of the endocyclic six-membered ring, the geometry-based methods exhibit even worse correlation with the NICS aromaticity. Apparently, the fact that each $\mathrm{CC}$ bond is part of two annellated rings with different aromaticities makes the system rather complex

Results calculated at other levels of theory do not show any significant differences, neither in relative, nor in absolute NICS values or geometry-based indices. (See Tables S1-4 and Figures S1-6), thus to obtain results for larger systems even smaller basis sets can be used.

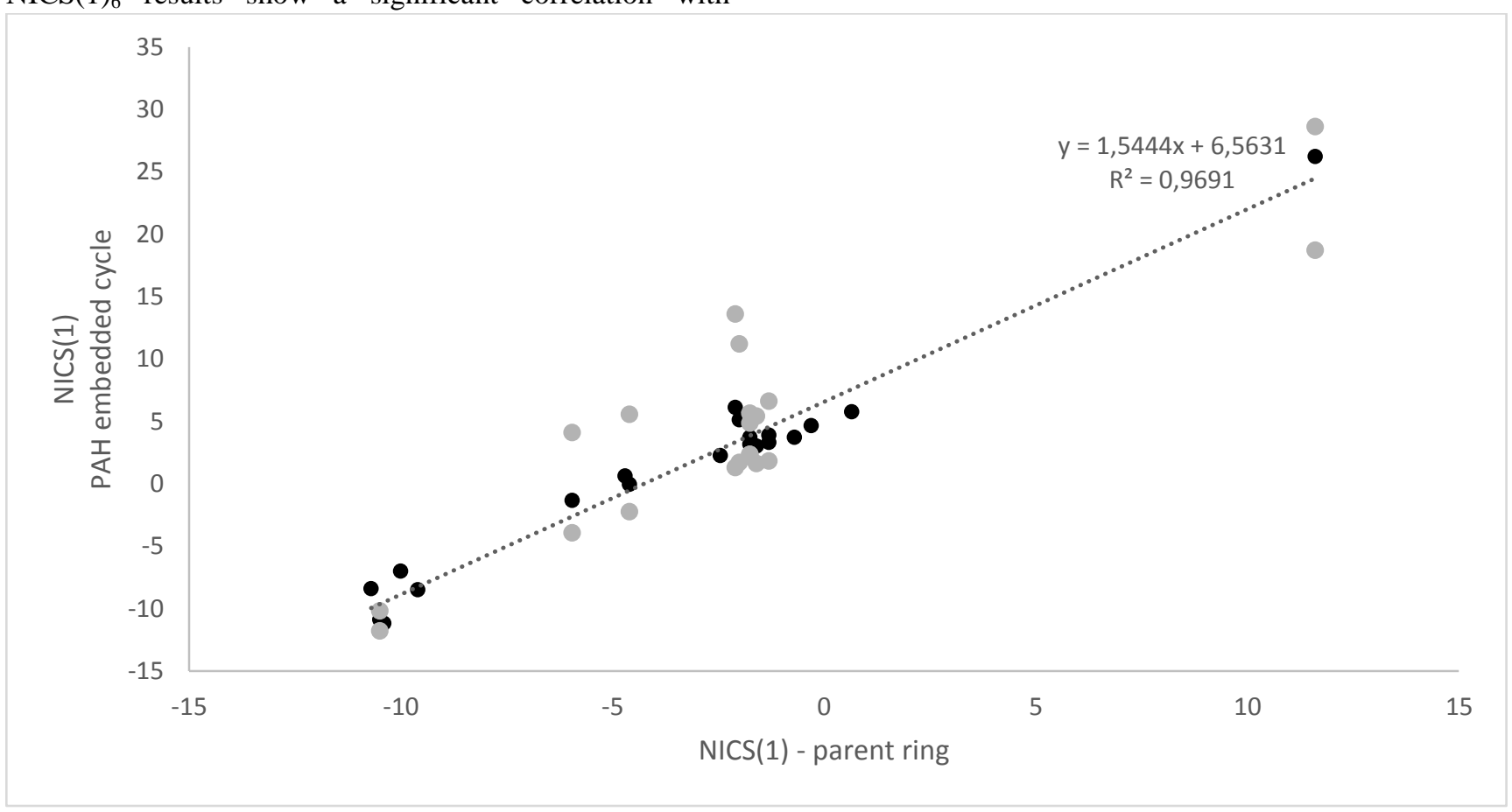

Figure 6: Correlation between the NICS(1) aromaticity of the parent and PAH embedded five-membered rings (B3LYP/cc-pVTZ) Grey dots correspond with $-\mathrm{F}$ and $-\mathrm{SiH}_{3}$ substituted systems, which are not included in the linear regression 


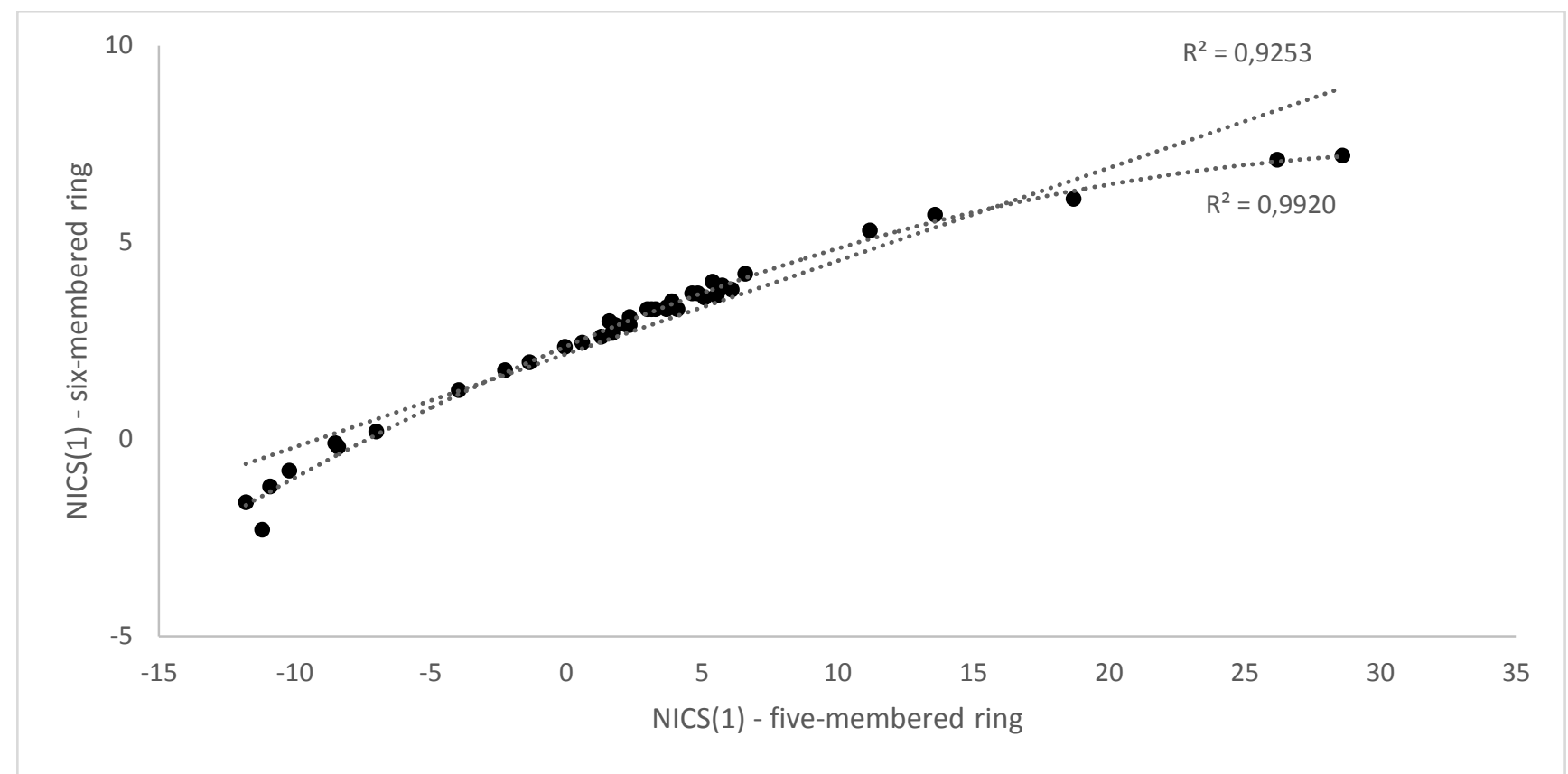

Figure 7: Correlation between the five-membered and the endocyclic six-membered ring's NICS (1) aromaticity (B3LYP/cc-pVTZ)

\section{Conclusion}

Aromaticity studies carried out on the condensed model system 2 with different heteroatoms showed that the $\mathrm{NICS}(1)_{5}$ aromaticity in the five-membered ring correlates with that in the parent five-membered ring having the same heteroelement. Although the local aromaticity pattern is clearly determined by the Clar structure, as evidenced by the local aromaticity values in the reference molecules R13, the modifying effect of the heteroatom is significant. The correlation between the $\mathrm{NICS}(1)_{5}$ and $\operatorname{NICS}(1)_{6}$ aromaticities of the neighbouring rings is excellent, by modification of the heterocycle, we can engineer the aromaticity of the connecting six-membered ring as well. Geometry based aromaticity indices do not correlate well with NICS values probably due to annellation effects between rings with different aromatic character. Calculations with the different tested basis sets don't show significant differences, therefore the use of the computationally cheaper methods is envisaged during further investigations of corresponding systems with extended $\pi$-framework.

\section{Acknowledgements}

This work is supported by Balaton PHC (830386K) TÉT_12_FR-1-2013-0017; OTKA NN 113772; Campus France; TAMOP-4.2.1/B-09/1/KMR-2010-0002 and COST-STSM-CM1302.

\section{References}

1. Wu J, Pisula W, Müllen K (2007) Chem Rev 107:718-747
2. Rocke AJ (2014) Angew Chem Int Ed Engl 54:46-50

3. Schleyer P von R (2001) Chem Rev 101:1115-1118

4. Schleyer P von R (2005) Chem Rev 105:3433-3435

5. Krygowski TM, Szatylowicz H, Stasyuk OA, Dominikowska J, Palusiak M (2014) Chem Rev 114:6383-6422

6. Wassmann T, Seitsonen A, Saitta A, Lazzeri M, Mauri F (2008) Phys Rev Lett 101:096402

7. Kertesz M, Choi CH, Yang S (2005) Chem Rev 105:3448-3481

8. Garcia-Borràs M, Osuna S, Luis JM, Swart M, Solà M (2014) Chem Soc Rev 43:5089-5105

9. Osuna S, Torrent-Sucarrat M, Ewels CP, Solà M, Geerlings P, Van Lier G (2009) J Nanosci Nanotechnol 9:6078-6083

10. Solà M (2013) Front Chem 1:22

11. Matsuo Y, Tahara K, Nakamura E (2003) Org Lett 5:31813184

12. Martín-Martínez FJ, Fias S, Van Lier G, De Proft F, Geerlings P (2012) Chemistry 18:6183-6194

13. Shimizu A, Hirao Y, Kubo T, Nakano M, Botek E, Champagne B (2012) Int. Conf. Comput. METHODS Sci. Eng. 2009 (ICCMSE 2009). AIP Publishing, pp 399-405

14. Konishi A, Hirao Y, Nakano M, Shimizu A, Botek E, Champagne B, Shiomi D, Sato K, Takui T, Matsumoto K, Kurata H, Kubo T (2010) J Am Chem Soc 132:11021-11023

15. Draper SM, Gregg DJ, Madathil R (2002) J Am Chem Soc 124:3486-3487 

Lett 11:5686-5689

17. Davis NKS, Thompson AL, Anderson HL (2011) J Am Chem Soc 133:30-31

18. Dou C, Saito S, Matsuo K, Hisaki I, Yamaguchi S (2012) Angew Chem Int Ed Engl 51:12206-12210

19. Escande A, Ingleson MJ (2015) Chem Commun 51:6257-6274

Dral PO, Kivala M, Clark T (2013) J Org Chem 78:1894-1902

Nyulászi L (2001) Chem Rev 101:1229-1246

Nyulászi L, Hollóczki O, Lescop C, Hissler M, Réau R (2006) Org Biomol Chem 4:996-998

Bouit P-A, Escande A, Szücs R, Szieberth D, Lescop C, Nyulászi L, Hissler M, Réau R (2012) J Am Chem Soc 134:6524-6527

Riobé F, Szűcs R, Bouit P-A, Tondelier D, Geffroy B, Aparicio F, Buendía J, Sánchez L, Réau R, Nyulászi L, Hissler M (2015) Chem Eur J 21:6547-6556

Plasser F, Pašalić H, Gerzabek MH, Libisch F, Reiter R, Burgdörfer J, Müller T, Shepard R, Lischka H (2013) Angew Chem Int Ed Engl 52:2581-2584

27. Nyulászi L, Schleyer P von R (1999) J Am Chem Soc 121:6872-6875

Katritzky AR, Barczynski P, Musumarra G, Pisano D, Szafran M (1989) J Am Chem Soc 111:7-15

Katritzky AR, Feygelman V, Musumarra G, Barczynski P, Szafran M (1990) J für Prakt Chemie 332:853-869

Katritzky AR, Feygelman V, Musumarra G, Barczynski P, Szafran M (1990) J für Prakt Chemie 332:870-884

Katritzky AR, Barczynski P (1990) J für Prakt Chemie 332:885-897

Katritzky AR, Szafran M, Anders E, Malhotra N, Chaudry SU (1990) Tetrahedron Comput Methodol 3:247-269

Katritzky AR, Karelson M, Wells AP (1996) J Org Chem 61:1619-1623

34.

Katritzky AR, Karelson M, Sild S, Krygowski TM, Jug K (1998) J Org Chem 63:5228-5231 (2002) J Org Chem 67:1333-1338

Schleyer P von R, Maerker C, Dransfeld A, Jiao H, Hommes NJR van E (1996) J Am Chem Soc 118:6317-6318

37. Schleyer P von R, Jiao H, Hommes NJR van E, Malkin VG, Malkina OL (1997) J Am Chem Soc 119:12669-12670
38. Poater J, Fradera X, Duran M, Solà M (2003) Chem Eur J 9:1113-1122

39. Gaussian 09, Revision B.01, M. J. Frisch, G. W. Trucks, H. B Schlegel, G. E. Scuseria, M. A. Robb, J. R. Cheeseman, G Scalmani, V. Barone, B. Mennucci, G. A. Petersson, H. Nakatsuji, M. Caricato, X. Li, H. P. Hratchian, A. F. Izmaylov, J. Bloino, G. Zheng, J. L. Sonnenberg, M. Hada, M. Ehara, K. Toyota, R. Fukuda, J. Hasegawa, M. Ishida, T. Nakajima, Y. Honda, O. Kitao, H. Nakai, T. Vreven, J. A. Montgomery, Jr., J. E. Peralta, F. Ogliaro, M. Bearpark, J. J. Heyd, E. Brothers, K. N. Kudin, V. N. Staroverov, T. Keith, R. Kobayashi, J. Normand, K. Raghavachari, A. Rendell, J. C. Burant, S. S. Iyengar, J. Tomasi, M. Cossi, N. Rega, J. M. Millam, M. Klene, J. E. Knox, J. B. Cross, V. Bakken, C. Adamo, J. Jaramillo, R. Gomperts, R. E. Stratmann, O. Yazyev, A. J. Austin, R. Cammi, C. Pomelli, J. W. Ochterski, R. L. Martin, K. Morokuma, V. G. Zakrzewski, G. A. Voth, P. Salvador, J. J. Dannenberg, S. Dapprich, A. D. Daniels, O. Farkas, J. B. Foresman, J. V. Ortiz, J. Cioslowski, and D. J. Fox, Gaussian, Inc., Wallingford CT, 2010 .

40. Becke AD (1993) J Chem Phys 98:5648-5652

41. Lee C, Yang W, Parr RG (1988) Phys Rev B 37:785-789

42. Hollóczki O, Nyulászi L (2011) Struct Chem 22:1385-1392

43. Moran D, Stahl F, Bettinger HF, Schaefer HF, Schleyer P v R (2003) J Am Chem Soc 125:6746-6752

44. Chen Z, Wannere CS, Corminboeuf C, Puchta R, Schleyer P von R (2005) Chem Rev 105:3842-3888

45. Bird CW (1985) Tetrahedron 41:1409-1414

46. Bird CW (1986) Tetrahedron 42:89-92

47. Bird CW (1987) Tetrahedron 43:4725-4730

48. Bird CW (1992) Tetrahedron 48:335-340

49. Gordy W (1947) J Chem Phys 15:305-310 Nyulászi L, Várnai P, Veszprémi T (1995) J Mol Struct THEOCHEM 358:55-61 